\title{
A New Species of Scaleworm, Grubeulepis malayensis (Annelida: Polychaeta: Eulepethidae), from Morib Beach, Malaysia, Living in Chaetopterid Tubes
}

\author{
Eijiroh Nishi \\ Coastal Museum of Natural History, \\ Yoshio, Katsuura, Chiba, 299-5242 Japan \\ Present and corresponding address: Manazuru Marine Laboratory \\ for Science Education, Yokohama National University, \\ Iwa, Manazuru, Kanagawa, 259-0202 Japan \\ E-mail:enishi@ynu.ac.jp
}

(Received 14 July 2000; Accepted 27 December 2000)

\begin{abstract}
A new species of eulepethid polychaete, Grubeulepis malayensis, is described. It lives in empty tubes of the chaetopterid polychaete Mesochaetopterus selangolus (Rullier, 1976) collected from a sandy beach at Morib Beach, near Kuala Lumpur, Malaysia. The species is distinguished by the lack of papillae on the first pair of elytra, possession of spinous notopodial hooks, and the presence of acicular neurochaetae on segments 2 to 5 . It is unique in its genus in possessing a single pair of prostomial eyes and in having a short anal cirrus on the right side.
\end{abstract}

Key Words: Scaleworm, new species, Polychaeta, Eulepethidae, Grubeulepis, Malaysia, chaetopterid tubes.

\section{Introduction}

Rullier (1976) established a new genus and species of Chaetopteridae, Sasekumaria selangola Rullier, 1976, from Morib Beach, Malaysia. This chaetopterid genus was considered unique because the body was thought to be divided into two regions rather than three as in all other genera in the Chaetopteridae. During my revisional work on the Chaetopteridae of Japan and adjacent areas, Dr. A. Sasekumar of the University of Malaya kindly sent me specimens of $S$. selangola with associated crabs and scaleworms. Based on these specimens and some of the type specimens studied by Rullier (1976), all of which have three body regions, I recently synonymized Sasekumaria with Mesochaetopterus (Nishi 1999). Rullier (1976) noted the presence of a porcellanid crab and a scaleworm in the tubes of $M$. selangolus (see also Petersen and Britayev 1997); later the crab was described as a new species, Polyonyx vermicola Ng and Sasekumar, 1993 ( $\mathrm{Ng}$ and Sasekumar 1993). The associated scale worm is described herein as a new species of Eulepethidae.

According to Pettibone (1969, 1986), eulepethid scaleworms are characterized by a unique type of branchial cirri found only on non-elytrigerous chaetigers; 
parapodia having characteristic hooked notoaciculae, hammer-shaped neuroacicular distal plates, and stout, bent notochaetae; and a pygidium having a single long, minutely papillate anal cirrus. The prostomium and first tentacular segment are withdrawn into segments $2-4$, and segment 3 is fused middorsally with the adjacent segments.

Eulepethid scaleworms have been recorded from several regions in the southern and western Pacific. These worms include Eulepethus hamifera (Grube, 1875) from the Philippines, Gulf of Tonkin, and East China Sea (Grube 1875; Pettibone 1969, 1986; Uschakov 1972); Mexieulepis amioi (Imajima, 1974) from Japan (Imajima 1974; Pettibone 1986); and Pareulepis malayana (Horst, 1913) from the Malay Archipelago (Horst 1913; Pettibone 1969, 1986). The new species is the fourth record of eulepethid scaleworm from the region and the second record of possible commensalism in the family following the association of Grubeulepis geayi (Fauvel, 1918) with the acoetid polychaete, Acoetes melanotus (Grube, 1876) at Madagascar (Day 1962).

\section{Systematics \\ Genus Grubeulepis Pettibone, 1969 \\ Grubeulepis malayensis n. sp.}

(Figs 1-4)

Materials. Holotype (CMNH-ZW-248; Coastal Museum of Natural History, Katsuura, Chiba) and a paratype (Department of Zoology, University of Malaya), sandy flat, Morib Beach, Malaysia, 5 December 1996, coll. A. Sasekumar.

Description. Holotype $30 \mathrm{~mm}$ long for 38 segments, $8 \mathrm{~mm}$ wide excluding chaetae, $10 \mathrm{~mm}$ wide including chaetae, tapering posteriorly. Paratype similar, 28 $\mathrm{mm}$ long for 40 segments, $8 \mathrm{~mm}$ wide including chaetae. Sex of type specimens unknown. Elytra and elytrophores 12 pairs on segments 2, 4, 5, 7, 9, 11, 13, 15, 17, 19, 21, 24; first pair oval without papillae (Fig. 1A); rest of elytra becoming more elongate posteriorly, with 5-16 lateral fimbriate processes arranged between anterior and posterior rounded lobes; processes non-articulated (Fig. 1B-G). Branchiae 10 pairs on segments $6,8,10,12,14,16,18,20,22,23$, inflated, with distal branchial cirrus (Fig. 2I). Dorsal cirri 2 pairs, on segments 3 and 6, subulate (Fig. 2G). Posterior dorsal lamellae beginning on segment 26, subcordiform to subconical (Fig. 2J).

Prostomium covered by segment 2; median antenna short, oval, arising anterodorsally on prostomium; lateral antennae conical, nearly triangular, arising terminally; palps elongate-tapered, extending beyond tentacular cirri; one pair of small eyes anterolaterally; nuchal organs short, lateral to prostomium (Fig. 2A). Tentacular parapodia (segment 1) narrower basely, enlarged distally, each with dorsal and ventral tentacular cirri subequal in length, 2 aciculae, and 2 bundles of spinous capillary chaetae (Fig. 2D). Ventral buccal cirri on segment 1 (Fig. 2E) thicker and larger than those following (Fig. 2F).

Parapodia biramous, supported by pale amber-colored noto- and neuropodial aciculae. Notopodial aciculae with hooked tips. Notopodial capillary chaetae spinous, forming long, spreading bundles emerging from posterior parts of notopodia. Stout, pale amber-colored notopodial hooks beginning on segment 2, spinous, tapering distally to either fine or flattened, spatulate tips (Figs 3E, 4A-E). Neuropodial aciculae with hammer-shaped distal plates (Fig. 4F). 


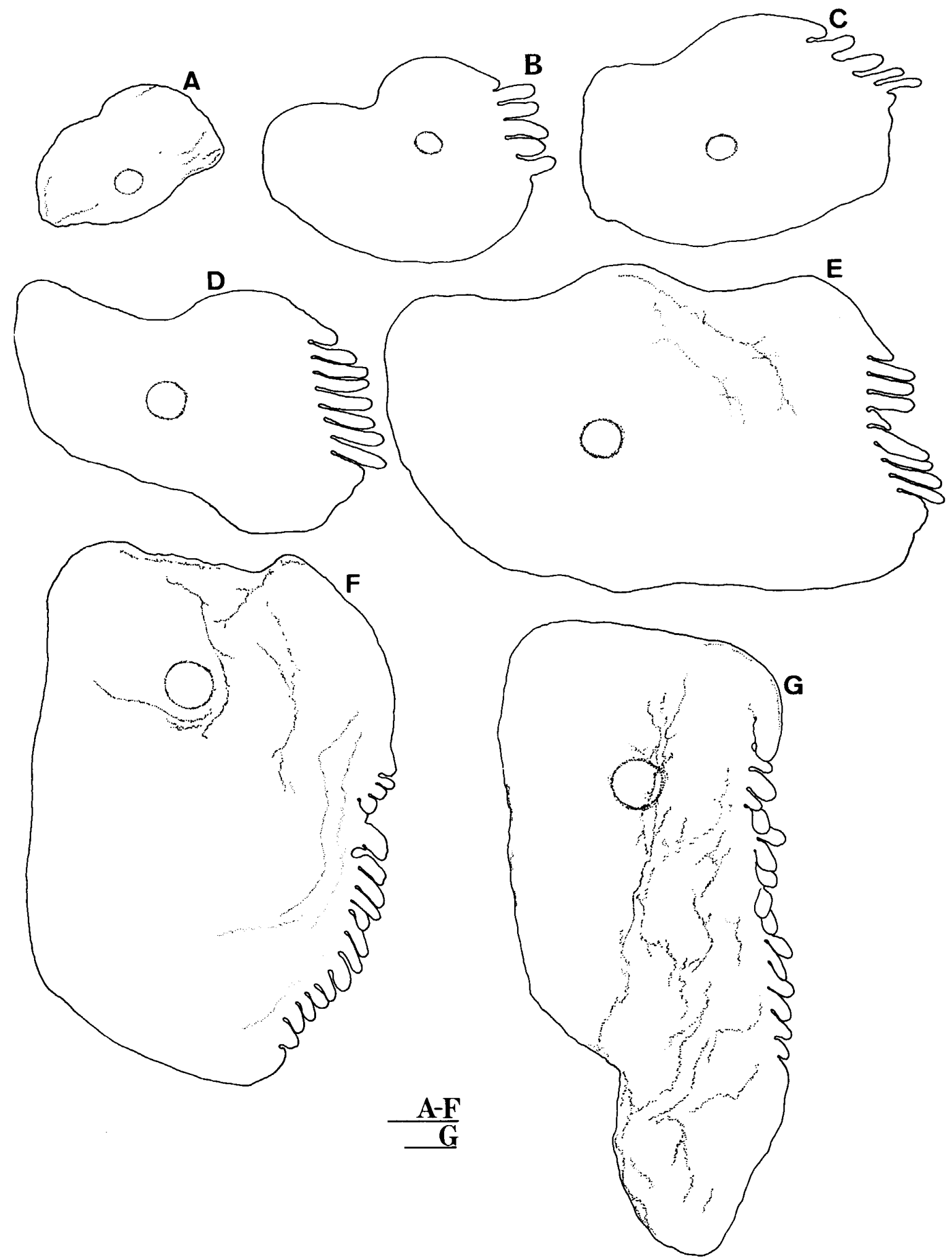

Fig. 1. Grubeulepis malayensis n. sp., right elytra of holotype. A-D, elytra 1-4; E, F, G, elytra 6,11 , and 12 , respectively. Scales: $A-G=0.5 \mathrm{~mm}$. 
Neurochaetae of several kinds: 1-2 upper pectinate chaetae (Fig. 3C); flattened chaetae with long, tapered tips on anterior parapodia (Fig. 3B); simple chaetae with pseudo-articulation (Fig. 3A); lower neurochaetae with rows of spinules (Fig. 3D); limbate and non-limbate chaetae with tapering tips; 1-2 dark, acicular neurochaetae each on segments 2-5. Upper neurochaetae of posterior region much stouter than lower ones, curved downwards, tapering to fine tips, finely spinous along bend. Pygidium with single short, smooth anal cirrus on right side (Fig. 2J). Pharynx not extended in types, shown extracted from trunk (Fig. 2B, C), with 20 pairs of elongate papillae and 2 pairs of plate-like chitinous ridges (jaws) (Fig. $2 \mathrm{C}$ ).

Habitat. Living in empty parchment tubes of the chaetopterid Mesochaetopterus selangolus.

Etymology. The species is named malayensis for the type locality, Malaysia.

Remarks. The diagnostic characters of the ten described species of Grubeulepis are summarized in Table 1. Grubeulepis malayensis is characterized by the number of branchiae, the absence of papillae on the first elytra, the segment in which the posterior lamellae first appear, and the spinous notopodial hooks (Table 1).

It is unique in being the only known member of its genus with only a short pygidial cirrus rather than an elongated pygidial cirrus or one of each. When only one cirrus is present, it is long and on the right side. If a short cirrus is also present, it is on the left side. Grubeulepis malayensis is most similar to G. ecuadorensis Pettibone, 1969 and $G$. westoni Pettibone, 1986. It can be distinguished from $G$. ecuadorensis by the presence of spinous notopodial hooks and from $G$. westoni by the number of segments with acicular neurochaetae. The presence of a single pair of eyes in $G$. malayensis is an additional unique character within the genus; $G$. ecuadorensis has three pairs and $G$. westoni has two to three pairs (Pettibone 1969, 1986).

\section{Acknowledgements}

I am grateful to Dr. A. Sasekumar for providing the scaleworm specimens, to Dr. M. H. Pettibone, Mr. E. Ruff, Dr. M. E. Petersen, and an anonymous reviewer for their critical reading and helpful suggestions on the manuscript, and to Ms. M. Nishi for typing the manuscript. This work was partly supported by a Grant-in-Aid for Encouragement of Young Scientists, No. 09740645, from The Ministry of Education, Science, Sport and Culture, Japan, and the subvention to biological research by RIMI (Research Institute of Marine Invertebrates), Tokyo.

Fig. 2. Grubeulepis malayensis n. sp., holotype. A, dorsal view of anterior end with elytra 2; $\mathrm{B}$, extended pharynx, ventral view; $\mathrm{C}$, distal right half of pharynx, inner view; D, right tentaculophore (segment 1), outer view; $\mathrm{E}-\mathrm{H}$, right elytrigerous parapodia of segments $2(\mathrm{E}), 3(\mathrm{G}), 5$ (F), and $7(\mathrm{H})$; I, branchiae of right cirrigerous parapodium of segment 14, dorsal view; J, posterior region of body, segments 24 to 38 , dorsal view. Scales: A-C $=1 \mathrm{~mm} ; \mathrm{D}-\mathrm{J}=0.5 \mathrm{~mm}$. Abbreviations: ac, anal cirrus; br, branchia; brc, branchial cirrus; buc, buccal cirrus; dc, dorsal cirrus; dtc, dorsal tentacular cirrus; e, eye; ely, elytron; j, jaw; la, lateral antenna; ma, median antenna; no, nuchal organ; pl, posterior lamella; vc, ventral cirrus; vtc, ventral tentacular cirrus; 1 , segment $1 ; 2$, segment 2 . 


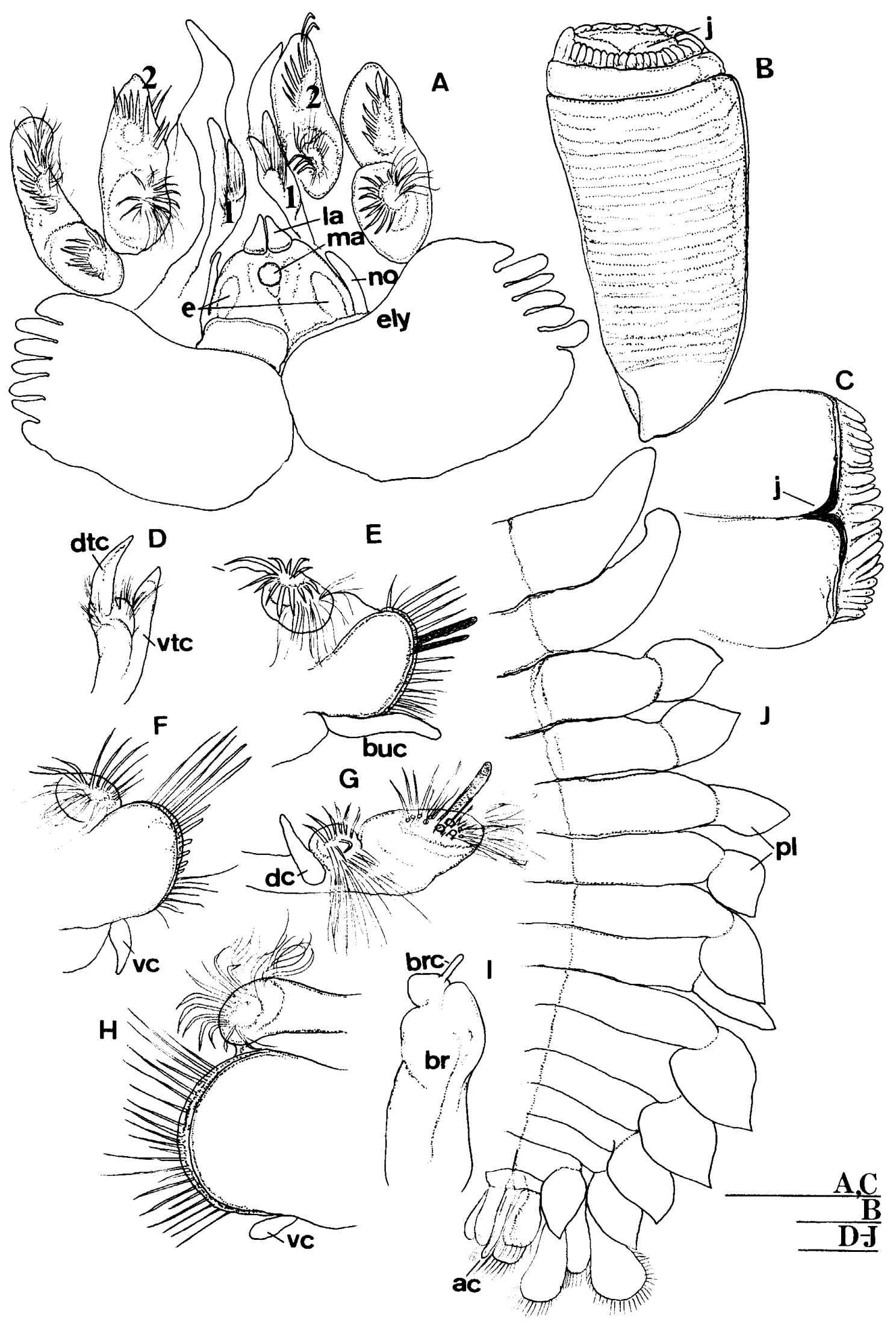



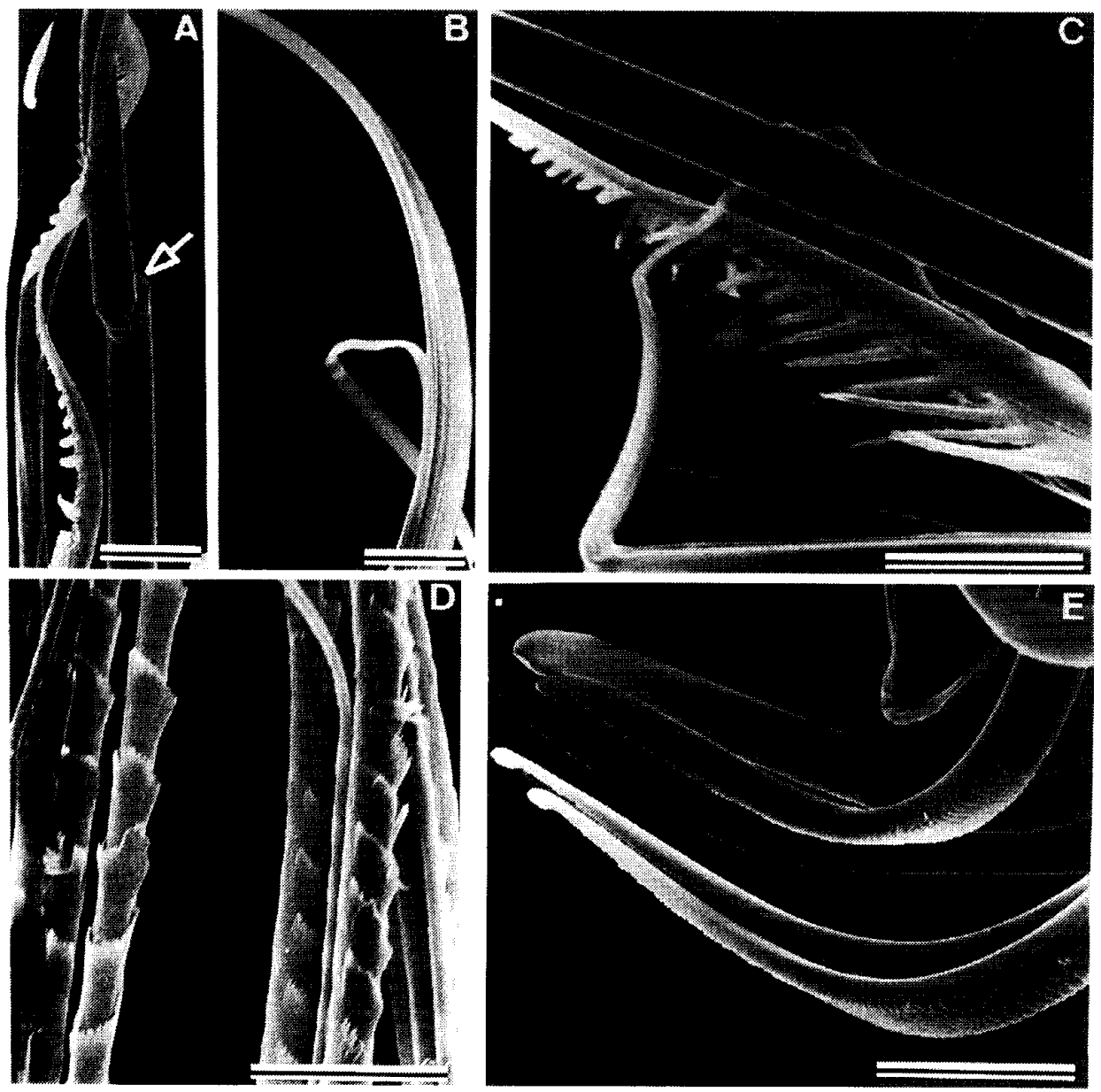

Fig. 3. Grubeulepis malayensis n. sp., scanning electron micrographs of chaetae of segments 5 and 13 of paratype. A, pectinate and slender chaetae, latter with pseudoarticulation (arrow); B, long, curved upper neurochaetae of segment 5; C, pectinate neurochaetae of segment 5; D, lower neurochaetae of segment 13; E, dorsal notopodial hooks of segment 5 . Scales: $\mathrm{A}, \mathrm{B}, \mathrm{E}=50$ $\mu \mathrm{m} ; \mathrm{C}=30 \mu \mathrm{m} ; \mathrm{D}=20 \mu \mathrm{m}$.

\section{References}

Berkeley, E. and Berkeley, C. 1939. On a collection of Polychaeta, chiefly from the west coast of Mexico. Annals and Magazine of Natural History, Series II 3: 321-346.

Day, J. H. 1962. Polychaeta from several localities in the western Indian Ocean. Proceedings of the Zoological Society of London 139: 627-656.

Grube, A. E. 1875. Bemerkungen über die Familie der Aphroditeen (Gruppe Hermionea und Sigalionina). Jahres-Bericht der Schlesischen Gesellschaft für Vaterlandische Cultur 52: $57-79$.

Horst, R. 1913. On two remarkable species of Aphroditidae of the Siboga Expedition. Notes from the Leiden Museum 35: 161-168.

Imajima, M. 1974. Occurrence of species of three families, Eulepethidae, Apistobranchidae, and Heterospionidae (Polychaeta) from Japan. Bulletin of the National Science Museum, Tokyo, Series A 17: 57-64. 

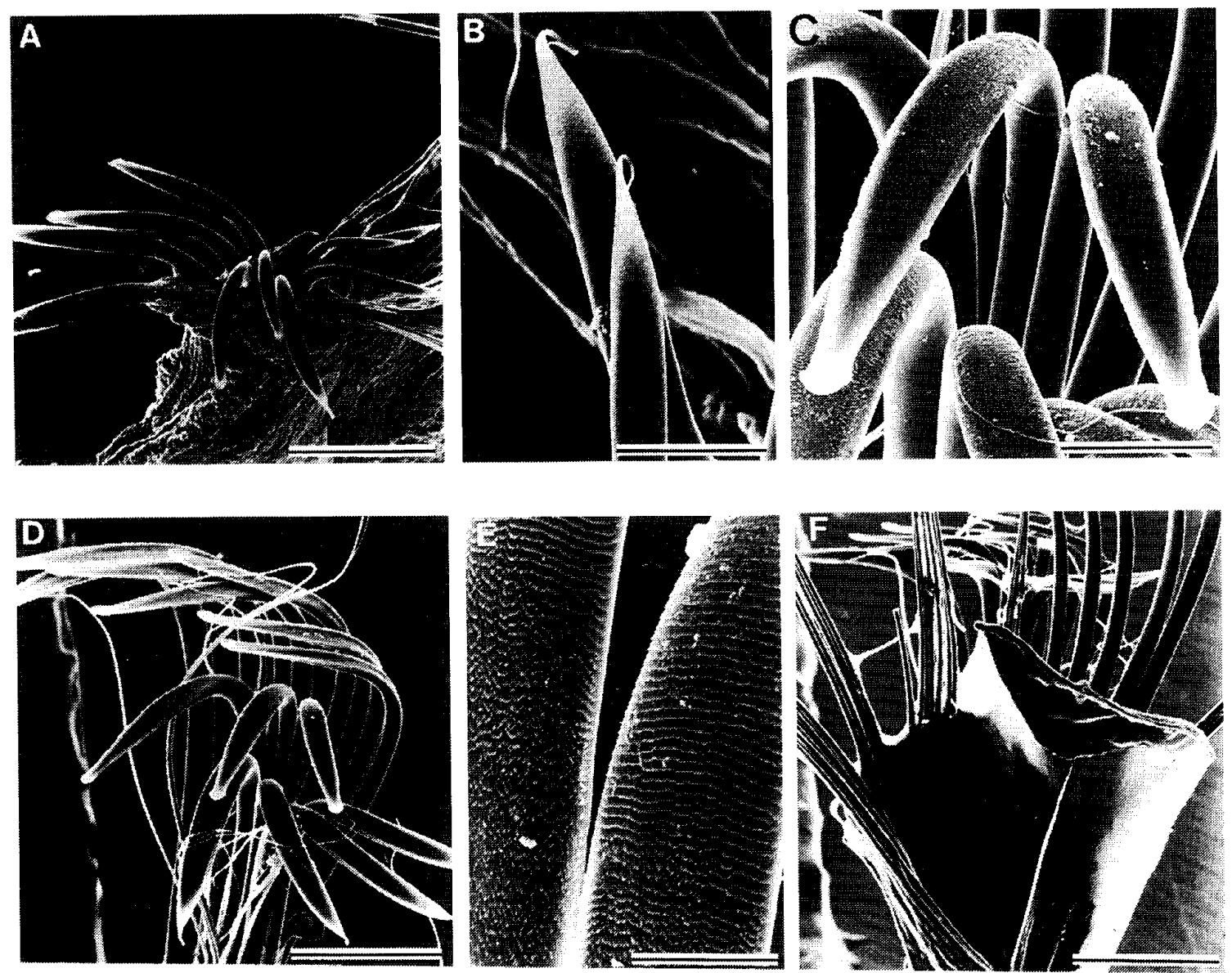

Fig. 4. Grubeulepis malayensis n. sp., scanning electron micrographs of chaetae of segments 13 and 31 of paratype. A-C, notopodial hooks of segment 13; A, entire group; B, detail of hooks of lower row; C, detail of dorsal surface of hooks of upper row. D-F, notopodial hooks of segment 31; D, entire group; E, detail of surface of hook of upper row; F, ventral view of neuropodium showing triangular tip of acicula. Scales: $\mathrm{A}=250 \mu \mathrm{m} ; \mathrm{B}, \mathrm{C}=50 \mu \mathrm{m} ; \mathrm{D}=150 \mu \mathrm{m} ; \mathrm{E}=30$ $\mu \mathrm{m} ; \mathrm{F}=200 \mu \mathrm{m}$.

Jones, M. L. 1962. On some polychaetous annelids from Jamaica, the West Indies. Bulletin of the American Museum of Natural History 124: 169-212.

Ng, P. K. L. and Sasekumar, A. 1993. A new species of Polyonyx Stimpson, 1858, of the P. sinensis group (Crustacea: Decapoda: Anomura: Porcellanidae) commensal with a chaetopterid worm from Peninsular Malaysia. Zoologische Mededelingen 67: 467-472.

Nishi, E. 1999. Redescription of Mesochaetopterus selangolus (Polychaeta: Chaetopteridae), based on type specimens and recently collected material from Morib Beach, Malaysia. Pacific Science 53: 24-36.

Petersen, M. E. and Britayev, T. A. 1997. A new genus and species of polynoid scaleworm commensal with Chaetopterus appendiculatus Grube from the Banda Sea (Annelida: Polychaeta), with a review of commensals of Chaetopteridae. Bulletin of Marine Science 60: 261-276.

Pettibone, M. H. 1969. Revision of the aphroditoid polychaetes of the family Eulepethidae Chamberlin (=Eulepidinae Darboux $=$ Pareulepidae Hartman). Smithsonian Contributions to Zoology 41: 1-44. 


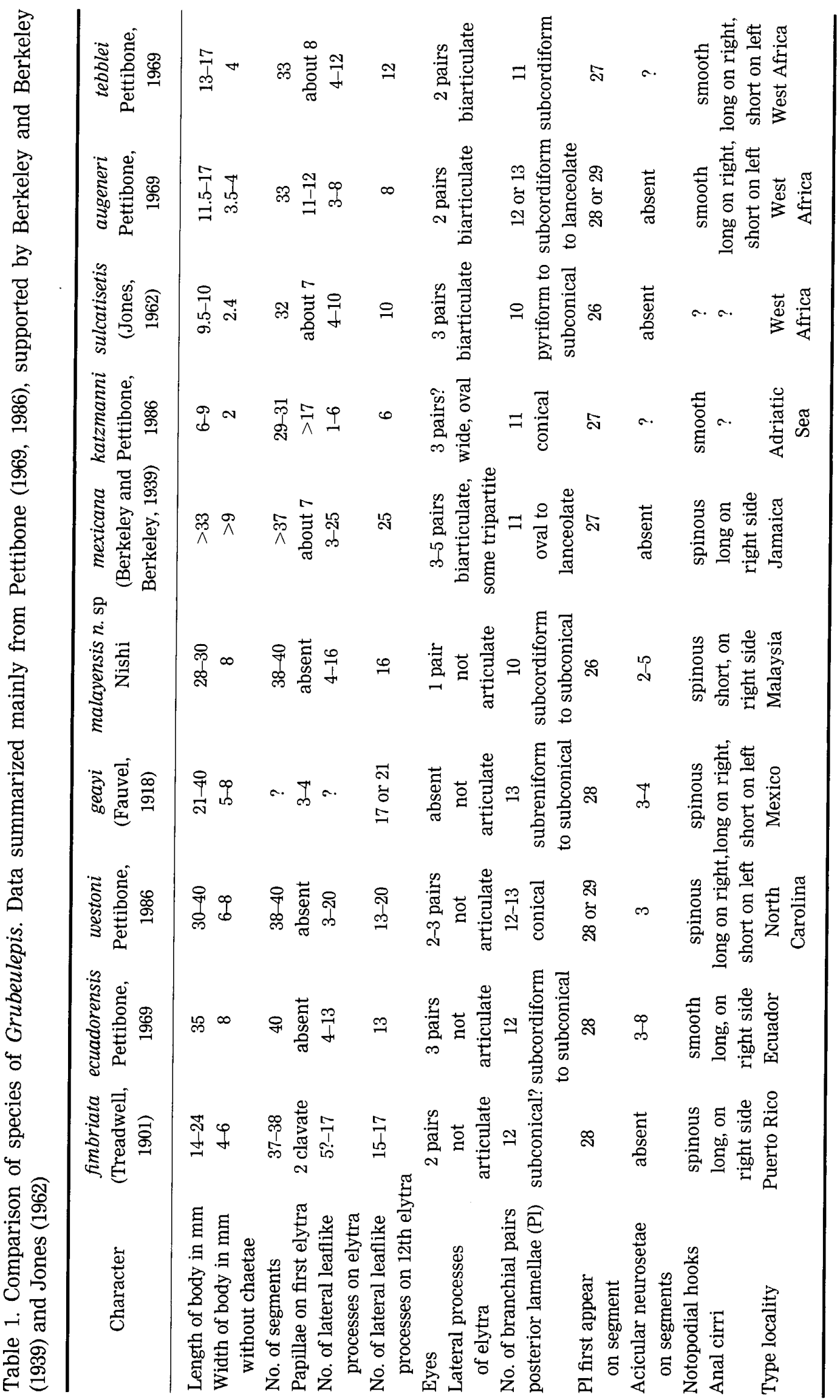


Pettibone, M. H. 1986. Additions to the family Eulepethidae Chamberlin (Polychaeta: Aphroditacea). Smithsonian Contributions to Zoology 441: 1-51.

Rullier, F. 1976. Description d'une nouvelle espèce de Chaetopteridae Sasekumaria selangola (Annélides Polychètes) de Malaisie. Bulletin de la Société Zoologique de France 101: 199-202.

Uschakov, P. V. 1972. On new occurrence of Eulepethus hamifera (Grube)(Polychaeta, fam. Eulepethidae Chamberlin). Issledovaniia Fauny Morei 18: 329-339. [In Russian, with English summary] 